\title{
1 Exploring the language and pedagogical models suitable for EMI in Chinese-speaking higher education contexts
}

\author{
Joyce Shao Chin and Naihsin Li
}

\section{Introduction}

The global spread of English has had a significant impact on higher education (HE) worldwide. English has been increasingly used as a vehicular language to transmit academic knowledge at tertiary institutions throughout the world. In the process, the role of English has been recast from an "object" of instruction in English classes to a "medium" of instruction in subject content classes. Dearden (2014, p. 4) proposes the following working definition of English as a medium of instruction (EMI):

The use of the English language to teach academic subjects in countries or jurisdictions where the first language (L1) of the majority of the population is not English.

Although Dearden (2014) applies the definition to EMI at all levels of education, this working definition, for two reasons, provides a proper starting point for a discourse on EMI at the tertiary level. First, this definition excludes the use of English as a second language (L2) to teach academic content in countries such as Australia, Canada, the UK, and the US, where English is the predominant L1, and thus places its primary focus onto EMI in non-native English speaking (NNES) contexts. This emphasis on NNES contexts is crucial to our discussion of EMI. As our review of the global development of EMI will show, differences in the role of English in education have resulted in context-specific problems and considerations in EMI implementation. A lot of these problems and considerations deserve our particular attention when conceiving the language and pedagogical models suitable for EMI in Chinesespeaking contexts. Furthermore, Dearden's (2014) definition draws a conceptual distinction between EMI and Content and Language Integrated Learning (CLIL), another term associated with teaching subject content through an additional language. Whereas CLIL emphasizes its "dual-focused" approach to advancing both content and language learning (Coyle et al., 2010, p. 1), 
the primary aim of EMI, as the above definition implies, is on the mastery of subject content. Dearden and Macaro (2016) reiterate the centrality of academic content and stress that EMI makes "no direct reference to the aim of improving students' English ability" (p. 456). Brown and Bradford (2017), examining several definitions of EMI in the literature, conclude that English language improvement has generally been perceived in these definitions only as "an implicit or incidental outcome" (p. 330).

Nonetheless, as this book focuses on tertiary-level EMI in NNES contexts, the particularity of tertiary education, coupled with the constraints resulting from students'-and sometimes teachers'-insufficient English proficiency, suggests the need to go beyond Dearden's (2014) definition and rethink language use in EMI at universities in NNES countries and regions. In the first place, the cognitive and linguistic demands of academic studies in tertiary education are substantially higher than those in primary and secondary education. University study entails the acquisition of a new skill set for constructing and transmitting academic knowledge, one which involves higher-order cognitive processing skills and discipline-specific communication conventions. The acquisition of these academic competencies can be challenging for native speakers of English entering higher education (Reason et al., 2006). For NNES students in EMI classes, limited English proficiency further increases the linguistic and cognitive loads of their academic studies. A substantial number of empirical studies have revealed the difficulties NNES students experienced in comprehending and communicating about course content in EMI classes (Chang, 2010; Evans \& Morrison, 2011a; Huang, 2018; Li \& Wu, 2017). These difficulties consequently pose pedagogical challenges to teachers, who generally lack the expertise to address language-related learning problems, and sometimes might not have adequate command of English to deliver EMI.

Further complicating the matter is an over-optimistic view about EMI prevalent in Asian universities. Whereas EMI, by definition, does not aim for English language improvement, it is often implemented in Asian HE contexts with the expectation of improving domestic students' English proficiency. In other words, it is believed that EMI can maximize students' exposure to English and, further, lead to improvements in their English proficiency. This expectation is observed not only in studies examining teachers' and students' perceptions of EMI (Lei \& Hu, 2014; Li \& Wu, 2017), but also in governmental-level EMI-related policies promulgated by many countries and jurisdictions in Asia (Byun et al., 2011; Tsou \& Kao, 2017; Zhao \& Dixon, 2017). In Chinese-speaking contexts, as EMI is often termed "whole" English instruction in Chinese - although officially termed a "bilingual course" in China (Zhao \& Dixon, 2017, p. 1) - it is often practiced, or expected to be practiced, as English-only instruction so as to provide students with an English immersion experience in an English as a foreign language (EFL) context. There have been mixed findings regarding the effectiveness of EMI in improving English proficiency (Huang, 2015; Lei \& Hu, 2014; Li, 2017). However, a growing body of evidence, as aforementioned, suggests that the 
delivery of such programs to NNES students, Chinese-speaking students included, has led to new pedagogical challenges and learning problems.

These problems and challenges go beyond the scope of a monoglossic English-centric view of EMI and call for a heteroglossic non-English-centric perspective. The concept of translanguaging deserves our attention. Originally from the Welsh term trawsieithu, translanguaging has been increasingly used in education to refer to "the process by which bilingual students perform bilingually in the myriad multimodal ways of classrooms - reading, writing, taking notes, discussing, signing, etc.” (García, 2011, p. 147). In a study investigating the adoption of translanguaging practices in a bilingual high school in the US, García and Sylvan (2011) report the observation that "students use diverse language practices for purposes of learning, and teachers use inclusive language practices for purposes of teaching" (p. 397, emphasis added). For tertiary-level EMI instruction in an EFL context, the most immediate implication of translanguaging is that students and teachers should be encouraged to draw on their full linguistic repertoires, including using their first languages, to cope with the demands of English-medium learning and teaching. A more effective pedagogy of translanguaging, as mapped out in García and Li (2014), requires systematic planning of translanguaging strategies to facilitate the construction of and communication about content knowledge.

This section begins with a reexamination of Dearden's (2014) working definition of EMI in connection with the challenges of tertiary-level EMI in NNES contexts. The problems identified through the reexamination indicate the inadequacy of an English-only approach to EMI, and the concept of translanguaging gives a perspective for conceiving an alternative approach more viable for NNES universities. With these challenges, problems, and perspectives in mind, we will first trace the development of EMI in NNES contexts and then explore the growth and impacts of EMI in Chinesespeaking contexts.

\section{The development of EMI in NNES contexts}

The past three decades have witnessed an exponential growth of EMI practices in tertiary education in countries and regions where English is learned as a foreign language. This growth has been documented in a number of multinational studies. Dearden (2014), using British Council staff as informed participants, reported that 44 out of the 55 participating countries and regions allowed EMI provision at both public and private universities. Studyportals, a Dutch-based organization, investigated their database of information on 1,000 universities at the top of international rankings and identified almost 8,000 courses being offered in English in 2016 at leading universities in NNES countries (Mitchell, 2016).

The phenomenal growth of EMI in tertiary education in EFL countries can be attributed to various reasons. Although great diversity exists in different 
education settings, the following driving forces behind EMI policies have frequently been cited in recent literature (e.g., Galloway et al., 2017; Macaro et al., 2018; Wächter \& Maiworm, 2014):

- raising the international profile and competitiveness of the university;

- attracting foreign students by lifting language barriers for their enrollment (to compensate for shortages of domestic students);

- increasing the international mobility and employability of students, faculty and staff;

- creating "brain gain" by attracting foreign students and faculty who could contribute to the future work force;

- gaining access to the exchanges of academic knowledge and to the domain of research publications where English is the dominant lingua franca;

- enhancing the intercultural competencies of domestic students; and

- improving the English proficiency of domestic students.

Among the above seven driving forces, the first six are directly related to HE internationalization. ${ }^{1}$ As we will see in the following descriptions of the EMI development in Europe and Asia, EMI provision has been perceived as both the instrument for and indicator of HE internationalization, but the actual outcomes are far more complex. As for the last driving force, the improvement of domestic students' English proficiency, as pointed out in the discussion of EMI definition in the previous section, was initially considered merely a side benefit of EMI. However, in practice, EMI has frequently been implemented, especially in Asian universities, with the expectation of improving the English abilities of local students. Issues related to this expectation will be further explored in the review of EMI in Asian and Chinese-speaking contexts.

\section{EMI in European universities}

In Europe, the adoption of the Bologna Declaration in 1999 by 29 European countries stimulated the widespread expansion of EMI in tertiary institutions. The supra-national declaration aimed to enhance the comparability of HE systems in Europe by converging the degree structures of European universities. This "convergence" process has encouraged the provision of EMI and English-taught programs (ETPs), as these practices have been perceived to remove the language obstacles hindering the mobility of students, faculty, and staff among universities in European countries. The substantial growth of ETPs in Europe was systematically tracked in Wächter and Maiworm's comparative studies in 2007 and 2014 (Wächter \& Maiworm, 2007, 2014). ${ }^{2}$ The results found a massive $239 \%$ increase in the numbers of ETPs over seven years, from 2,389 in 2007 to 8,089 in 2014 (Wächter \& Maiworm, 2014).

Considering that international mobility is central to the drive toward EMI in Europe, the student-mix data derived from Wächter and Maiworm's (2014) survey deserves further attention. First, in terms of overall student intake, 
$54 \%$ of the students enrolled in the surveyed courses were foreign students. Furthermore, among the 8,089 ETPs identified in the study, approximately $5 \%$ enrolled only domestic students, whereas about $10 \%$ enrolled only foreign students. These data indicate that most of the ETPs surveyed had a mix of foreign and domestic students, which created a context for English to function as the academic lingua franca.

However, as noted in Hultgren's (2019) critical review, EMI has been imposed, rarely with well-planned strategies, on faculty, staff, and students in European universities. Therefore, the increased use of EMI has drawn mixed views from these stakeholders, including concerns about its negative impacts. One of these concerns noteworthy for our discussion of EMI in Chinese-speaking contexts is the domain loss of L1 - that is, the dominance of English as the hegemonic language of communication at the expense of the home language. Wilkinson (2013) cites a decision at a Dutch university to offer new programs in European Studies and European Public Health only in EMI, under the influence of an earlier decision to close programs in economics and business in Dutch and provide solely their parallel EMI programs. For the aforementioned domains, Wilkinson (2013) points out, English-only instruction will constrain the availability of materials on local issues due to the reduced use of texts in home languages. For universities in China and Taiwan where most students share a common L1, domain loss is a crucial issue when planning the roles of L1 in EMI classes.

The above review of the development of EMI in European universities demonstrates that English fulfilled the need for an academic lingua franca among a mix of foreign and domestic students in the ETPs surveyed. However, this role of English as the academic lingua franca also aroused anxiety over the domain loss of L1 due to the hegemony of English as the language of scholarship. These issues are particularly pertinent to the following discussion of the use of EMI in Asian universities and in Chinese-speaking contexts.

\section{EMI in Asian universities}

Over the past two decades, the Asia-Pacific has also seen the mushrooming of EMI at universities in NNES countries and regions. As in the case of Europe, EMI has played a central role in the internationalization of Asian universities. Governments across the Asia-Pacific have promulgated various initiatives and policies to exert influence in the planning and implementation of EMI at tertiary institutions, as illustrated in the following examples in Japan and Korea.

In Japan, the Ministry of Education, Culture, Sports, Science and Technology (MEXT) launched the Global 30 Project in 2009 with the purpose of attracting 300,000 international students to study at top-ranking universities by 2011 through the increased provision of EMI. When the Global 30 Project failed to achieve its intended outcome, it was succeeded by another project in a similar vein, the Top Global University Project, in 2014. At the 
same time, many universities not included in these government projects also began to adopt EMI, although for slightly different reasons. As pointed out in Chapple (2015), in addition to recruiting international students, many universities envisioned the potential of EMI to improve Japanese students' English proficiency through the immersion context provided.

In 2007, the South Korean government announced its strategic plan for the internationalization of Korean universities. Byun et al. (2011) examined the relevant government documents and summarized the following rationale for promoting EMI in HE, which included: (1) preparing students for their future careers by boosting their "internationally-oriented skills" (p. 432); (2) attracting visiting scholars to teach and international students to study; and (3) enhancing the language skills and confidence of faculty members in order to raise their abilities to interact in the global academic world.

The above brief review of EMI policies in Japan and South Korea, in the first place, demonstrates the top-down policy decisions involved in EMI, akin to those in Europe, but at the national level. Another point for reflection is the expectation expressed by governments and universities that EMI can help to enhance the English proficiency of domestic students by maximizing their exposure to English. The same expectation has also been reported in research on the use of EMI in many other Asian universities. In the next section, we will delve into the development of EMI in three HE contexts where the majority of the students are Chinese-speaking: China, Taiwan, and Hong Kong.

\section{The growth and impact of EMI in Chinese-speaking contexts}

To cope with global competition, the internationalization of universities in China, Taiwan, and Hong Kong has accelerated at a fast pace over the past two decades, stimulated by numerous government initiatives. However, in terms of EMI implementation, differences in the status of English due to historical reasons have resulted in divergent paths of development in these three Chinese-speaking contexts. In China and Taiwan, where English is a foreign language and Chinese is the predominant language of instruction in primary and secondary schools, the processes of implementing EMI in tertiary education and its growth patterns are similar to those of Japan and Korea. Hong Kong, though, is a different story. As a former British colony returned to China in 1997, it has a long history of the coexistence of Englishand Chinese-medium schools. Hong Kong's experiences in bilingual education give a perspective valuable for universities in China and Taiwan when considering the roles of English and Chinese in their specific EMI contexts.

It should be noted here that Singapore, though with an ethnic Chinese majority, will not be included in the following discussion of EMI in the Chinese-speaking contexts. The rationale for this exclusion is related to the preeminence of English in education in Singapore and its impact on the status of other major languages. ${ }^{3}$ As part of the government's ongoing effort to consolidate the position of English as the lingua franca in this multilingual 
nation, a unified language policy was promulgated in 1987, which stipulated English as the sole medium of instruction for all levels of education (Bolton \& Botha, 2017). A noteworthy effect of this "English and mother tongue" policy, revealed in the General Household Survey in 2015, is the increasing use of English as the home language. The 2015 survey found English has become the most frequently spoken language at home for $36.9 \%$ of residents, up from $32.2 \%$ in 2010 and just ahead of Mandarin, at 34.9\%. The prevalence of English in daily life indicates Singapore has a linguistic ecology which is quite distinct from that of China, Taiwan, and Hong Kong. Hence, the following sections will focus on the development paths of EMI in these three Chinese-speaking contexts.

\section{EMI in China}

The first government guidelines in China to promote EMI in undergraduate programs were issued by the Ministry of Education in 2001. Specific requirements were further stipulated in the Assessment Standards for Undergraduate Education in Chinese Higher Institutions (henceforth referred to as the Assessment Standards) published in 2004. The Assessment Standards require that in designated disciplines, at least $10 \%$ of the courses offered should be delivered in EMI. However, it should be noted that in the above document, the EMI course was defined as "a course that adopts English textbooks and in which the English instruction time exceeds $50 \%$ of all class time" (Zhao \& Dixon, 2017, p. 3).

On the basis of these government guidelines, universities across China have been endeavoring to offer EMI throughout the past two decades. In 2006, a survey commissioned by the Chinese Ministry of Education showed that 132 out of the 135 participating universities had implemented EMI courses, averaging 44 courses in each university (Wu et al., 2010; Zhao \& Dixon, 2017). More recently, according to the information provided in the Study in China website, 620 undergraduate EMI degree programs were being offered in 2018 by 127 universities in 25 provinces in China (Study in China, 2018).

A more nuanced study by Rose et al. (2020) has shown a mixed picture as regards the current and future development of EMI in Chinese universities. This study, investigating 63 Chinese universities, found that the pace of growth varied according to the needs of individual institutions, and some senior administers even predicted a slowdown in EMI growth rates in the future. More significantly but somewhat contradictorily, a policy analysis of 93 university-level EMI documents showed an increased use of "all English" and "bilingual and/or all English" and a decreased use of "bilingual teaching/ instruction" in policy documents produced after 2009 (Rose et al., 2020, p. 14). This indicates a shift in policy toward English-only programs, away from the bilingual models of EMI stipulated in the 2004 Assessment Standards. This emerging trend deserves our particular attention when considering the proper roles of L1 in EMI classes. 


\section{EMI in Taiwan}

In Taiwan, the first government announcement of the EMI initiative appeared in the Challenge 2008: National Development Plan issued by the Executive Yuan in 2002. According to the plan, the intended outcome of EMI provision in tertiary education was "to promote college students' English proficiency and broaden their international perspectives" (Executive Yuan, 2002). In a recent and more ambitious blueprint, approved by the Executive Yuan in 2018 to develop a bilingual Taiwan by 2030, one of the key strategies is the introduction of a Chinese-English bilingual learning environment and the adoption of immersive teaching methods at all levels of education (Executive Yuan, 2018). These policies across almost two decades reflect the twofold rationale behind adopting EMI we have seen in the cases of Japan and Korea. In the first place, Taiwan, like many countries and regions in the Asia-Pacific, has recognized the crucial role of EMI in HE internationalization. More importantly, the motivation to enhance students' English abilities through EMI, once again, has been embedded in policy making.

Since 2002, various incentives have been provided by the government to promote EMI implementation. The government's encouragement has resulted in the remarkable growth of EMI in Taiwan's tertiary education. In terms of the number of EMI courses, there was a sharp rise from 16,450 courses in 2009 to over 24,077 courses in 2014 (Ministry of Education, Taiwan, 2015; Tsou \& Kao, 2017). Meanwhile, the number of EMI degree programs in Taiwanese universities increased from 115 programs in 2005 to 332 programs in 2014 (Ministry of Education, Taiwan, 2015).

Nonetheless, it is noteworthy that in 2019, there were 31,811 international students attending degree programs in Taiwan, which constituted only $2.6 \%$ of the total student enrollment (Ministry of Education, Taiwan, 2019). This fact indicates that the majority of students enrolled in EMI courses are domestic students. The implications of this are twofold. First, the learning experiences of Taiwanese students, particularly the challenges they face and the support they need, should be crucial considerations in any discussions about EMI. Furthermore, in an EMI context where Chinese-speaking students constitute the majority, the supportive roles of their L1 should be explored. Both of these implications will be covered in the discussions of the challenges of EMI in Chinese-speaking contexts in the next section.

\section{EMI in Hong Kong}

In Hong Kong, over $95 \%$ of the population is ethnic Chinese, with Cantonese as the most common home language. Historical developments over the past 150 years have brought the people in Hong Kong unique experiences concerning the medium of instruction (MoI).

English was de facto the only official language until 1974, when Chinese was recognized as a co-official language. During this period, most secondary 
schools and universities adopted EMI. There were several attempts over the decades by parents and schools to push for the use of the mother tongue (i.e., Cantonese) as an MoI, but most of the attempts failed. The most plausible reason for this was that the universities, except for the Chinese University of Hong Kong, taught most subjects in English. To prepare students for their future academic needs, most secondary schools ended up adopting EMI. Kirkpatrick (2014) remarks that this "laissez-faire" approach exemplifies how the MoI at the tertiary level can influence the choice of MoI at the secondary level (p. 19).

After Hong Kong was handed back to China in 1997, the Hong Kong SAR government mandated a new language policy of bi-literacy (written Chinese and English) and tri-lingualism (English, Cantonese, and Putonghua) (Xu, 2014). Since then, policies on the use of MoI in primary and secondary schools have swung from limiting the number of EMI schools in 1997 to allowing flexibility in adopting EMI in 2008 and 2009.

At the tertiary level, however, despite the government's continuing efforts to promote bi-literacy and tri-lingualism, the majority of public and private universities are officially English-medium. This seemingly paradoxical phenomenon, as pointed out in Mok and Cheung (2011), can be ascribed to the policy of establishing Hong Kong as a regional education hub to attract more international students and create brain gain. Evans (2000) commented on the status of English and EMI after 1997 and predicted that "since English will continue to play an important role in the upper echelons of business, the professions and tertiary education in the SAR, Hong Kong parents and students will continue to regard a successful English-medium education as a prerequisite for socio-economic advancement" (p. 200). Nonetheless, Evans and Morrison's (2011a) study on students' language use in and outside classrooms at an EMI university suggests despite the growing numbers of international students and lecturers' efforts to deliver whole-English instruction, students are not motivated to speak English except for the need to communicate with international or non-Cantonese-speaking students. Even inside the classroom, Evans and Morrison (2011a) found that many of the lectures in English were delivered as one-way communication with little interaction, and in seminars, students mainly use Cantonese and a mixture of English and Cantonese to conduct group discussions. The above findings indicate that without supportive learning resources, the immersion environment provided by EMI alone may not help to enhance students' ability and motivation to communicate in English. On the contrary, the enforcement of English-only instruction might impede classroom interactions.

The above review of EMI development in China, Taiwan, and Hong Kong illustrates how EMI policies have been enforced via top-down decisions and, in the implementation process, interacted with various social and educational drivers, such as aspirations for HE internationalization, expectations of improving English abilities, and the wrestling to maintain or enhance the status of the different languages and cultures involved. The rapid expansion 
of EMI in Chinese-speaking contexts, as aforementioned, has prompted a substantial growth of empirical studies investigating the implementation and effects of EMI in tertiary education. These studies have uncovered the experiences and perspectives of students and teachers in EMI classes and also highlighted the significance of context-specific considerations in planning the language and pedagogical models to be used in an EMI course. These issues will be explored in the following section.

\section{Challenges of EMI in Chinese-speaking contexts}

Studies have shown that Chinese-speaking students generally hold positive attitudes toward EMI as they are aware of the positive effects of EMI on their English competence, which further benefits their future career or academic pursuits. On the other hand, these studies also reveal the problems with learning in the EMI classroom. Specifically, students face a "double bind" predicament (Bailey et al., 2008) as they try to access new academic content through a language that remains relatively opaque to them, which often results in their limited, if not poor, understanding of the content. Thus, they often indicate difficulties in understanding technical vocabulary and comprehending lectures. In addition, students also have difficulties in expressing themselves orally and achieving an appropriate academic style in writing, mostly because of their limited English proficiency (Evans \& Morrison, 2011a; Li \& Wu, 2017). In fact, it is suggested that students may need to reach a threshold level of English proficiency to benefit from EMI (Lei \& Hu, 2014). However, students' readiness in terms of English proficiency is often overlooked in EMI programs. Moreover, even a good general English proficiency does not guarantee a painless learning experience in the EMI context, especially when students are used to communicating discipline-specific information in their first language (Evans \& Morrison, 2011b). Therefore, there is a role for courses on English for academic purposes (EAP) or English for specific purposes (ESP) to support students' learning in EMI (Evans \& Green, 2007).

Subject teachers in Chinese-speaking contexts also face challenges when they have to teach academic content in English. The teachers' performance will be evaluated in terms of not only their knowledge or skills in their professional domain but also how good their English is. Even when teachers have a sufficiently good command of English to run the classes, they will have to address language-related learning issues or assessment concerns, which appear to be more within EFL teachers' expertise. Therefore, EMI teachers need resources, such as development programs, to support their pedagogical needs in the EMI classroom. Collaboration between content and language teachers has been proposed as one remedy to students' learning issues in the EMI classroom (Cots, 2015; Wilkinson, 2013); however, relevant research has been scarce.

The use of English as the dominant instructional language in a classroom where teachers and students are non-English native speakers to a certain 
extent affects classroom interaction and the depth of content learning. Studies reveal that students are more likely to remain silent in EMI classrooms than in classrooms where Chinese is the instructional language $(\mathrm{Hu} \& \mathrm{Li}, 2017$; Huang, 2018). In other words, EMI classrooms tend to be monologic in nature, with few student-student or teacher-student interactions, a situation which may be detrimental to learning.

Universities play a critical role in facilitating the implementation of EMI. As EMI is enforced top-down (Tsou \& Kao, 2017; Zhao \& Dixon, 2017), universities face challenges in creating a school- or department-wide atmosphere receptive to this policy. Insufficient communication among the stakeholders, including policymakers, administrators, teachers, and students, in terms of the purposes, principles, practices, and expected outcomes of EMI may result in resistance or tension, such as in the case of the Chinese University of Hong Kong (Li, 2015). In addition to communication with stakeholders, universities need to consider the resources and support required by teachers and students and take necessary measures. Flexible application of the EMI policy should also be considered in terms of the nature and the curriculum of different disciplines and the role or functions of English in specific disciplines.

\section{Rethinking EMI in the Chinese-speaking higher education context}

An increasing number of studies have been conducted to examine the implementation of EMI in different institutions and across different disciplines, as well as the perceptions or attitudes toward EMI of stakeholders in these regions. The findings of these studies, though descriptive in nature, contribute to a mosaic picture of current EMI practice and highlight the challenges and concerns of stakeholders. We think the time is ripe for us to move one level down and conduct an in-depth examination of the essence of EMI in nonnative English-speaking contexts and its implementation from a curriculum point of view. We have observed considerable variation in expectations and support for EMI at the institutional level and in learning needs from mixed student bodies with varied levels of English proficiency. Therefore, the purpose of this book is to go one step further by addressing the issues observed in diverse disciplines and university settings - using practices in Hong Kong and Taiwan as leading examples for discussing how collaboration should be conducted within whole educational systems to accomplish successful EMI.

\section{Rethinking the means-end value of EMI}

The first aim of this book is to present critical perspectives on the nature of EMI in tertiary education in Chinese communities. There is no established consensus on some important issues regarding the nature of EMI, such as the exact role of English in the EMI classroom and its relation to the local language(s) in a bilingual/multilingual community, nor on the outcomes that stakeholders expect from EMI programs. For example, EMI is often practiced 
in the hope of enhancing students' English proficiency in addition to their subject knowledge. However, it is now seen as a double-edged sword in that it can improve students' language ability, on the one hand, but on the other hand, it can also compromise students' learning of subject knowledge (Tsou \& Kao, 2017; Zhao \& Dixon, 2017).

Therefore, we propose that in EMI courses, English should be used because it is an appropriate "medium" of instruction, but not because it is also an "object" of instruction (Fenton-Smith et al., 2017, p. 2). In addition, EMI should be adopted only when there is sufficient evidence that students are ready to use English as an appropriate vehicle for academic studies. This viewpoint has led to a discussion on the model of English (i.e., English as a lingua franca) and its expected degree of dominance in an EMI classroom in a NNES context. In particular, it is proposed that EMI should not be conceived of and practiced as English-only classes. Instead, the practice of EMI should be conceptualized as a continuum of English used to deliver content knowledge, with English-immersion courses as the realization of one end of the continuum and the different degrees of involvement of students' other linguistic resources in the remaining spectrum.

The aforementioned conceptualization of EMI echoes the concept of translanguaging reviewed in the first section of this chapter. A translanguaginginformed approach to EMI emphasizes the proper role of a student's first language. In fact, there are similar discussions in EMI literature. For example, a distinction is made between full EMI and partial EMI (see Pecorari \& Malmström, 2018). Nevertheless, we think that there can be more nuanced discussion about the choice, planning, and practice of the mediums of instruction in the EMI classroom. In particular, Kirkpatrick (2014) has made a distinction between medium of instruction and classroom language (CL), with the latter referring to the language of interaction between teacher and students and among students in the classroom. What we are trying to add to EMI practice is a proper status for the use of Chinese as a classroom language in Chinese-speaking contexts. This is where our concept of "continuum" converges into a translanguaging-informed approach to EMI.

Despite our emphasis on the role of L1, we still acknowledge that there is a need to support EFL students' learning of discipline-relevant academic English. In particular, there is a close interplay between knowledge of academic discourse/literacy and academic learning, as the mastery of disciplinespecific discourse is a prerequisite of deep academic understanding (Meyer et al., 2015; Mohan et al., 2010; Scardamalia \& Bereiter, 2006). However, the learning of English should not be incorporated as a curriculum goal of EMI courses, especially when the EMI teachers do not have the time or even the training to teach a foreign language. Therefore, instead of proposing a dual-focus on content and language in EMI courses, we prefer a "dual-track" model in which EMI courses and ESP/EAP courses serve their own functions (i.e., content learning and language learning, respectively), but with better integration of the course content as well as collaboration or communication 
between the content teachers and the language teachers. We believe that a dual-track system is more beneficial to students' advancement in their discipline expertise and academic English ability than a curriculum embedded with the dual goals of content and language learning (i.e., CLIL) at the tertiary level of education.

CLIL and EMI both involve content learning and the use of a foreign language as the instruction medium. However, there is a subtle but important difference. While CLIL, as a framework, is more on the side of student learning, in particular language learning, EMI, which is often practiced with global concerns, such as internationalization of the curriculum and attraction of non-local students, deems the learning of subject matter as more important. However, previous work on EMI mostly focused on the language learning side. For example, Tsou and Kao (2017) mostly address language issues in the EMI class. Similarly, Barnard and Hasim (2018) discuss EMI challenges and solutions from the perspective of applied linguistics. Though the role of language is important in EMI, we think that the success of EMI should depend on the learning outcome of the subject matter. Therefore, this book calls for a rethinking of EMI from the subject learning perspective.

As a synthesis of the viewpoints discussed in the above critical review of EMI in Chinese-speaking HE contexts, we propose the following modified definition of EMI, adapted from Dearden (2014), which better fits the purpose of this book:

EMI refers to the use of the English language to teach academic subjects in countries or jurisdictions where the first language (L1) of the majority of the population is not English. Its primary objective is on the mastery of subject content, with English language improvement as a secondary or incidental outcome. For tertiary education in NNES contexts, EMI is conceived as a continuum of English use to deliver academic content, rather than a practice of whole-English instruction. Having taken into account the academic demands of specific EMI contexts, the proper roles of English and the students' L1, together with other semiotic resources, should be pedagogically planned, along with the provision of EAP/ESP resources to support learning.

\section{Discipline-specific pedagogical issues and good practices in EMI}

This book is also devoted to providing guidelines for instructors who are facing pedagogical challenges in different EMI settings. Studies on the EMI classroom in NNES contexts have highlighted some common pedagogical challenges and discipline-specific concerns. In this book, experienced EMI teachers from various disciplines have been invited to demonstrate their pedagogical practices in addressing students' learning problems and to reflect on the contextual factors involved in refining their practices in the future. Implementing EMI in a wide variety of disciplines will be covered, including 
medical science, mathematics, health and physical education, computer science, creative arts, music education, business management, and linguistics. These EMI courses represent a spectrum of weak-to-strong English dominance, demonstrating various possibilities for EMI arrangements and how to serve their particular stakeholders. In addition to drawing on the valuable experiences of EMI subject instructors from different disciplines, this book integrates the perspectives of both content experts and language experts, which can effectively help to address issues concerning students' learning of content knowledge in a classroom conducted through a foreign language.

Another aspect discussed here is what constitutes successful EMI in a broader setting, beyond classroom practices. The discussion includes what qualifies as a successful EMI program and what prepares universities, teachers, and students for such a program. Discussions of these issues are highly relevant when policymakers must decide whether EMI is feasible and beneficial to all stakeholders.

\section{Chinese-speaking contexts: Taiwan and Hong Kong}

Discussions of these issues are also highly formulated in Chinese-as-L1 regions, contexts that are culturally and linguistically distinct from contexts where English is widely spoken as an L1. In particular, this book draws on the experiences of Taiwan and Hong Kong, where EMI has been implemented in a wide range of disciplines other than medical sciences and foreign language studies. In Taiwan, EMI has often been adopted by universities as a strategy to increase internationalization. While one major aim of implementing EMI is to recruit international students, most EMI programs in Taiwan target domestic students, making teachers in this context more aware of the pedagogical and learning problems that occur in the EMI classroom in an NNES setting. Hong Kong, on the other hand, has been facing an increase in the number of NNES students from non-local regions (e.g., China and other Asian countries) in its universities as a consequence of internationalization in recent years. These institutions have also developed measures to tackle teaching and learning problems in an EMI classroom. Moreover, with its extensive EMI experience and constant and in-depth discussion on the educational impacts of the medium of instruction (e.g., Tsui, 2004; Yip et al., 2003), Hong Kong's experience may enlighten other NNES regions on this issue.

\section{Overview of the chapters}

This volume consists of ten chapters. A brief description of each chapter is provided in the following paragraphs.

Chapter 2 discusses the expected learning outcomes and difficulties in implementing EMI in medical education in Taiwan. Specifically, the authors reflect on the best implementation of EMI in Taiwan medical education by considering the purpose of medical education — to foster students' ability to 
acquire the most up-to-date medical knowledge in order to serve the medical needs of the local community. Therefore, the best medical talents should be bilingual experts equipped with both professional skills and English competence. However, EMI should not be implemented as an English-only practice; on the contrary, English courses should be strategically integrated into a medical school curriculum in which students' first language still plays a role. The chapter further provides concrete advice on what should be done if EMI were to be implemented in Taiwanese medical schools.

Chapters 3 and 4 present cases in which content teachers and language teachers have worked collaboratively to support students' development of discipline-specific English competence in EMI contexts, either by generating necessary resources or by co-teaching in a classroom setting. Academic writing skills are of particular focus since academic writing is an essential element of the higher education context and Chinese-speaking students have shown prominent difficulties in mastering this skill, given that academic writing "requires a variety of subject-specific literacies."

The Technical Writing and Research Methods course presented in Chapter 3 demonstrates how a content teacher and a language teacher co-teach in a classroom setting to foster Information Engineering students' disciplinespecific writing skills in a Taiwanese university. It demonstrates a model of "team teaching" between a content teacher and a language teacher to help students develop academic writing styles and skills as required by their field of expertise, in particular the ability to adequately present their research. This chapter also delineates how the teachers clearly define the role of students' L1 and the role of English with respect to course delivery, teaching materials, students' oral presentations, and assignments, by taking into consideration students' language proficiency and language needs.

Chapter 4 presents a case in the Hong Kong higher education context in which a research team investigates how students' inadequate discipline-specific English language competence may have constrained their learning in EMI. As a result, the research team, content teachers, and language experts worked collaboratively to construct an online learning platform and workshops to support math students' summary writing skills in areas concerning the content and language quality of the summary. Interview data on students' perception of the usefulness of the resources provided indicate the insufficiency of EAP to support learning in EMI contexts and the need to address disciplinespecific language needs or language needs at different stages of education (undergraduates vs. postgraduates).

Chapters 5 and 6 reflect on the use of EMI in specific disciplines with regard to its possible benefits and challenges to subject learning. Chapter 5 provides a case study of pedagogical practice in the EMI classroom in the context of business management. The chapter presents the rationale behind adopting EMI in a business college and delineates challenges to it, such as diverse student backgrounds, large class sizes, and lack of teaching materials for local business cases. As case discussions are a common activity in business 
courses, this chapter specifically stresses the importance of creating an interactive classroom as a way to engage students in subject learning in an EMI context and further provides practical pedagogical guidelines for conducting interactive activities and assigning collaborative tasks.

Also rooted in the Taiwanese context, Chapter 6 reports on the implementation of EMI in linguistics programs in the Taiwan, where English is regularly employed as the instruction language and the professors and students are usually at an adequate level of English proficiency. The study surveyed linguistics professors and graduate students' perceptions of EMI in terms of its effect on their subject learning. The findings of the study highlight some critical factors that affect the effectiveness of EMI, including students' English proficiency and the complexity and nature of course content. The study also proposes that EMI is best implemented using a moderated approach with strategic switching between Chinese and English.

Assessment has been a less-researched area in studies related to EMI. Based on the review of assessment practices in EMI classrooms in Chinesespeaking contexts, Chapter 7 explores how the assessment concerns identified in such classroom settings can be addressed based on a learning-oriented approach. In particular, it proposes that the role of English in both instruction and assessment should be more carefully considered, more explicit evaluative criteria should be given, scaffolding should be provided to alleviate students' English difficulties, and effective feedback should be provided to foster learning and development. There is also a discussion of the support and resources necessary for enhancing and sustaining EMI teachers' professional development with regard to assessment.

Aware of the fact that students' readiness to take EMI courses lie not only in their English language proficiency, but also in the fusion of general language ability, subject knowledge, and cognitive capacity, Chapter 8 presents the framework of the Dynamic Language Ability System (DLAS), which on the one hand accommodates the complex interaction between language competence, disciplinary knowledge, and thinking competence, and on the other hand, caters to the evolving nature of core components and the interaction mechanism. The DLAS framework may have the potential to diagnose students' English language readiness for EMI study and to evaluate the efficiency of EMI programs.

Chapter 9 presents the case of a university in Hong Kong which switched the main medium of instruction from Classical Written Chinese and Cantonese to English. The chapter demonstrates the driving forces behind EMI-related policies (driven by socioeconomic rather than educational motives) and how the university has provided support to address the changes. By using surveys and interviews, the authors identify facilitators and barriers to effective change. In particular, the interview data still suggest the importance of using students' mother tongue as a learning resource to accommodate students' learning needs. The chapter demonstrates how a structured approach may minimize 
the process of trial and error for teachers and students and provides further insights into policy making and planning at the administrative level.

While EMI seems to be an irresistible trend, this book calls for a discussion on the forms of EMI that best suit the needs of NNES students, in particular Chinese-speaking students, in diverse disciplines and university contexts, in order to reach a mutually beneficial situation for universities and their students. As this book addresses the pedagogical challenges of EMI using examples drawn mainly from the Chinese-as-L1 contexts of Hong Kong and Taiwan, it will appeal to readers not only in these and other Chinese-speaking areas, but also to EMI universities in English-speaking and non-Englishspeaking countries where Chinese-speaking students constitute a significant proportion of the student body. Moreover, the perspectives discussed and proposed in this book are not limited to Chinese-speaking regions, but can also be extended to other NNES regions.

\section{Notes}

1 Altbach and Knight (2007) defines HE internationalization as a multidimensional process involving "the policies and practices undertaken by academic systems and institutions - and even individuals - to cope with the global academic environment" (pp. 290-291).

2 Wächter and Maiworm's studies in 2007 and 2014 narrowed the definition of ETPs to include only full degree programs at undergraduate and postgraduate levels which were taught entirely in English. The majority of these programs $(80 \%)$ were postgraduate. Only $20 \%$ were undergraduate programs.

3 According to Singapore's General Household Survey in 2015, 74.1\% of the population were of Chinese descent, speaking various dialects, $13.3 \%$ of Malay descent, $9.1 \%$ of Indian descent, and 3.3\% of other descent. The survey data is retrieved from www.singstat.gov.sg//media/files/publications/ghs/ghs2015/indicators.pdf.

\section{References}

Altbach, P. G., \& Knight, J. (2007). The internationalization of higher education: Motivations and realities. Journal of Studies in International Education, 11(3/ 4), 290-305. doi: 10.1177/1028315307303542

Bailey, F., Burkett, B., \& Freeman, D. (2008). The mediating role of language in teaching and learning: A classroom perspective. In B. Spolsky \& F. M. Hult (Eds.), The handbook of educational linguistics (pp. 606-625). Malden, MA: Blackwell.

Barnard, R., \& Hasim, Z. (2018). English medium instruction programmes: Perspectives from South East Asian universities. New York: Routledge.

Bolton, K., \& Botha, W. (2017). English as a medium of instruction in Singapore higher education. In B. Fenton-Smith, P. Humphreys, \& L. Walkinshaw (Eds.), English medium instruction in higher education in Asia-Pacific: From policy to pedagogy (pp. 133-152). Dordrecht, Netherlands: Springer.

Brown, H., \& Bradford, A. (2017). EMI, CLIL, \& CBI: Differing approaches and goals. In P. Clements, A. Krause, \& H. Brown (Eds.), Transformation in language 
education. Tokyo: JALT. Retrieved from https://jalt-publications.org/sites/default/ files/pdf-article/jalt2016-pcp-042.pdf

Byun, K., Chu, H., Kim, M., Park, I., Kim, S., \& Jung, J. (2011). English-medium teaching in Korean higher education: Policy debates and reality. Higher Education, 62(4), 431-449.

Chang, Y. Y. (2010). English-medium instruction for subject courses in tertiary education: Reactions from Taiwanese undergraduate students. Taiwanese International ESP Journal, 2(1), 55-84.

Chapple, J. (2015). Teaching in English is not necessarily the teaching of English. International Education Studies, 8(3), 1-13.

Cots, J. M. (2015). Introducing English-medium instruction at the University of Lleida, Spain: Intervention, beliefs and practices. In A. Doiz, D. Lasagabaster, \& J. M. Sierra (Eds.), English-medium instruction at universities: Global challenges (pp. 106-128). Bristol, UK: Multilingual Matters.

Coyle, D., Hood, P., \& Marsh, D. (2010). CLIL: Content and language integrated learning. Cambridge, UK: Cambridge University Press.

Dearden, J. (2014). English as a medium of instruction: A growing global phenomenon. London: British Council.

Dearden, J., \& Macaro, E. (2016). Higher education teachers' attitudes towards English medium instruction: A three-country comparison. Studies in Second Language Learning and Teaching, 6(3), 455-486. doi: 10.14746/sllt.2016.6.3.5

Evans, S. (2000). Hong Kong's new English language policy in education. World Englishes, 19(2), 185-204.

Evans, S., \& Green, C. (2007). Why EAP is necessary: A survey of Hong Kong tertiary students. Journal of English for Academic Purposes, 6, 3-17. doi: 10.1016/ j.jeap. 2006.11 .005

Evans, S., \& Morrison, B. (2011a). The student experience of English-medium higher education in Hong Kong. Language and Education, 25, 147-162.

Evans, S., \& Morrison, B. (2011b). Meeting the challenges of English-medium higher education: The first-year experience in Hong Kong. English for Specific Purposes, 30, 198-208.

Executive Yuan. (2002). The challenge 2008: National development plan. Taipei, Taiwan: Author.

Executive Yuan. (2018). Blueprint for developing Taiwan into a bilingual nation by 2030. Taipei, Taiwan: Author. Retrieved from https://bilingual.ndc.gov.tw/sites/bl4/files/ news_event_docs/blueprint_for_developing_taiwan_into_a_bilingual_nation_by_ 2030.pdf

Fenton-Smith, B., Humphreys, P., \& Walkinshaw, I. (2017). English medium instruction in higher education in Asia-Pacific: From policy to pedagogy. Dordrecht, Netherlands: Springer.

Galloway, N., Kriukow, J., \& Numajiri, T. (2017). Internationalisation, higher education and the growing demand for English: An investigation into the English medium of instruction (EMI) movement in China and Japan. London: British Council.

García, O. (2011). Educating New York's bilingual children: Constructing a future from the past. International Journal of Bilingual Education and Bilingualism, 14(2), $133-153$.

García, O., \& Li, W. (2014). Translanguaging: Language, bilingualism and education. New York: Palgrave Macmillan. 
García, O., \& Sylvan, C. (2011). Pedagogies and practices in multilingual classrooms: Singularities in pluralities. Modern Language Journal, 95(3), $385-400$.

Hu, G., \& Li, X. (2017). Asking and answering questions in English-medium instruction classrooms: What is the cognitive and syntactic complexity level? In J. Zhao \& Q. Dixon (Eds.), English-medium instruction in Chinese universities: Perspectives, discourse and evaluation (pp. 184-203). New York: Routledge.

Huang, D.-F. (2015). Exploring and assessing effectiveness of English medium instruction courses: The students' perspectives. Procedia-Social and Behavioral Sciences, 173, 71-78.

Huang, Y.-P. (2018). Resistance to English-medium instruction practices: A qualitative case study. Teaching in Higher Education, 23, 435-449. doi: 10.1080/ 13562517.2017.1421629

Hultgren, A. K. (2019). The drive towards EMI in non-English-dominant European HE: The role of university rankings. Language Teaching, 52(2), 233-236.

Kirkpatrick, A. (2014). English as a medium of instruction in East and Southeast Asian universities. In N. Murray \& A. Scarino (Eds.), Dynamic ecologies: A relational perspective on languages education in the Asia-Pacific region (pp. 15-29). Dordrecht, Netherlands: Springer.

Lei, J., \& Hu, G. (2014). Is English-medium instruction effective in improving Chinese undergraduate students' English competence? International Review of Applied Linguistics in Language Teaching, 52, 99-126.

Li, D. C. S. (2015). Linguistic hegemony or linguistic capital? Internationalization and English-medium instruction at the Chinese university of Hong Kong. In A. Doiz, D. Lasagabaster, \& J. M. Sierra (Eds.), English-medium instruction at universities: Global challenges (pp. 65-83). Bristol, UK: Multilingual Matters.

Li, M. (2017). Evaluation of learning outcomes in an education course. In J. Zhao \& Q. Dixon (Eds.), English-medium instruction in Chinese universities: Perspectives, discourse and evaluation (pp. 147-164). New York: Routledge.

Li, M.-Y., \& Wu, T.-C. (2017). Creating an EMI program in international finance and business management. In W. Tsou \& S.-M. Kao (Eds.), English as a medium of instruction in higher education: Implementation and classroom practices in Taiwan (pp. 21-38). Singapore: Springer.

Macaro, E., Curle, S., Pun, J., An, J., \& Dearden, J. (2018). A systematic review of English medium instruction in higher education. Language Teaching, 51(1), 36-76.

Meyer, O., Coyle, D., Halbach, A., Schuck, K., \& Ting, T. (2015). A pluriliteracies approach to content and language integrated learning-mapping learner progressions in knowledge construction and meaning-making. Language, Culture and Curriculum, 28, 41-57.

Ministry of Education, Taiwan. (2015). Statistics of international students (20052015). Retrieved from http://depart.moe.edu.tw/ed4500/cp.aspx?n=1B58E0B7366 $35285 \& \mathrm{~s}=\mathrm{D} 04 \mathrm{C} 74553 \mathrm{DB} 60 \mathrm{CAD}$

Ministry of Education, Taiwan. (2019). Statistics of international students (20072019). Retrieved from https://depart.moe.edu.tw/ED4500/cp.aspx?n=1B58E0B736 635285\&s=D04C74553DB60CAD

Mitchell, N. (2016, February 3). Universities compete by teaching in English. BBC. www.bbc.com/news/business-35429233 
Mohan, B., Leung, C., \& Slater, T. (2010). Assessing language and content: A functional perspective. In A. Paran \& S. Lies (Eds.), Testing the untestable in language education (pp. 217-240). Clevedon, UK: Multilingual Matters.

Mok, K., \& Cheung, A. (2011). Global aspirations and strategising for world-class status: New form of politics in higher education governance in Hong Kong. Journal of Higher Education Policy and Management, 33(3), 231-251.

Pecorari, D., \& Malmström, H. (2018). At the crossroads of TESOL and English medium instruction. TESOL Quarterly, 52, 497-515.

Reason, R. D., Terenzini, P. T., \& Domingo, R. J. (2006). First things first: Developing academic competence in the first year of college. Research in Higher Education, 47(2), 149-175. doi: 10.1007/s11162-005-8884-4

Rose, H., McKinley, J., Xu, X., \& Zhou, S. (2020). Investigating policy and implementation of English medium instruction in higher education institutions in China. London: British Council.

Scardamalia, M., \& Bereiter, C. (2006). Knowledge building: Theory, pedagogy, and technology. In K. Sawyer (Ed.), Cambridge handbook of the learning sciences (pp. 97-118). New York: Cambridge University Press. Retrieved from https://ikit.org/ fulltext/2006_KBTheory.pdf

Study in China. (2018). Study in China. http://studyinchina.cscse.edu.cn/

Tsou, W., \& Kao, S.-M. (2017). English as a medium of instruction in higher education: Implementations and classroom practices in Taiwan. Singapore: Springer.

Tsui, A. B. M. (2004). Medium of instruction in Hong Kong: One country, two systems, whose language? In J. W. Tollefson \& A. B. M. Tsui (Eds.), Medium of instruction policies: Which agenda? Whose agenda? (pp. 97-116). Mahwah, NJ: Lawrence Erlbaum Associates.

Wächter, B., \& Maiworm, F. (2007). English-taught programmes in European higher education: The picture in 2007. Bonn, Germany: Lemmens.

Wächter, B., \& Maiworm, F. (2014). English-taught programmes in European higher education: The state of play in 2014. Bonn, Germany: Lemmens.

Wilkinson, R. (2013). English-medium instruction at a Dutch university: Challenges and pitfalls. In A. Doiz, D. Lasagabaster, \& J. M. Sierra (Eds.), English-medium instruction at universities: Global challenges (pp. 3-24). Bristol, UK: Multilingual Matters.

Wu, P., Wang, S. G., Jiang, X., Zeng, D. J., Guan, Y. X., \& Li, X. F. (2010). Gaodeng xuexiao shuangyu jiaoxue de xianzhuang yanjiu he shijian tansuo [An exploratory study of English-medium instruction in Chinese higher education]. Beijing: Higher Education Press.

$\mathrm{Xu}, \mathrm{Z}$. (2014). Functional English and Chinese as mediums of instruction in a higher institution in Hong Kong. In K. Dunworth \& G. Zhang (Eds.), Critical perspectives on language education: Australia and Asia Pacific (pp. 209-228). Singapore: Springer.

Yip, D. Y., Tsang, W. K., \& Cheung, S. P. (2003). Evaluation of the effects of medium of instruction on the science learning of Hong Kong secondary students: Performance on the science achievement test. Bilingual Research Journal, 27, 295-331. doi: 10.1080/15235882.2003.10162808

Zhao, J., \& Dixon, Q. (2017). English-medium instruction in Chinese universities: Perspectives, discourse and evaluation. New York: Routledge. 